\title{
Adoption of Blockchain Technology in Trade Finance Process
}

\author{
A.V. Bogucharskov, I.E. Pokamestov, K.R. Adamova and Zh.N. Tropina
}

\author{
Department of Financial Markets and Banks, Financial University under the Government of the Russian \\ Federation, Moscow, Russia
}

\begin{abstract}
The complexity of trade finance instruments associated with need for many accompanying documents, constant coordination are problems of this process. Successful development of trade finance instruments depend on improvement of software and implement blockchain solutions that enable companies to unite and through partnerships and process automation to accelerate cash flow and documentation throughout supply chain. The paper aims to examine areas and ways of blockchain application in trade finance and to identify key aspects of improving transactions process. We present possible interaction of participants with digital letters of credit and factoring with blockchain application and display its effect on key trade finance instruments. Moreover, we identifies a number of problems, implementation solutions of which will lead to further more efficient application of technology in supply chain finance. The achieving these goals will lead to further more effective application of blockchain in financing of supply chain. Blockchain with a high level of functionality and security in trade finance processes reduces processing time for documents, transaction costs, expanding number of participants and increases level of transparency.
\end{abstract}

Keywords: Trade finance, factoring, blockchain, digital letter of credit, smart contract.

\section{INTRODUCTION}

Innovations have become a common element of company's activities in modern economy. Company, which aspires to become the first in its segment, to win a large market share, expand its customer base and be one step ahead of its competitors, must innovate in its processes. Application of innovations has become a factor in ensuring the economic sustainability of business, industry and the economy as a whole.

The introduction of innovations does not bypass such important area in the development of financial system, as trade finance. This is the most simple and convenient way to replenish working capital, which is an integrated measures in provision of financing for supply and purchase of goods or services. With the help of various tools related to trade finance, excluding the risk of non-receipt of the product or payment for the delivered goods.

The implementation of various innovative solutions in trade finance can solve existing problems in the economy, as this is one of the most effective tools for maintaining continuity of reproduction process. The inaccessibility of trade finance in replenishment of working capital among small and medium-sized enterprises in many areas is acutely felt. One of the reasons is a lack of reliable tools that provides transparency to eliminate asymmetric information problems. In addition, there are many other difficulties in the development of trade finance:

*Address correspondence to this author at the Department of Financial Markets and Banks, Financial University under the Government of the Russian Federation, Moscow, 127015, Moscow, Butirskaya str., 79, 182., Russia;

E-mail: bogucharskov92@mail.ru
First, the volumes of trade financing transactions are dynamic: external factors, such as interest rates, legislative changes and internal factors, such as limited capital and need of providing depreciation, influence development of the system.

Secondly, there is a difficulty in implementing trade financing in global supply chain. Implementation involves huge efforts for suppliers and integrates this process with finance, purchasing and IT departments of companies.

Thirdly, it is difficult to bring incentives to different participants. Suppliers, buyers and financiers are independent decision-makers seeking to maximize profits in terms of asymmetric structures, costs and uncertainties. Such independent profit maximizations often lead to poor performance of entire supply chain.

One of the most important factors on the way to solving these problems and the successful development of trade finance instruments is improvement of software and implement blockchain solutions that enable companies to unite and through partnerships and process automation to accelerate cash flow and documentation throughout supply chain.

The outline of this paper is as follows: Section 2 presents the literature review. Section 3 discusses background information about software products in trade finance. Section 4 presents the ways and the areas of blockchain application in trade finance. Section 5 presents ways to improve the application of technology in trade finance. The final section provides the conclusion. 


\section{LITERUTURE REVIEW}

Nakamoto (2008) invented blockchain for use in the cryptocurrency bitcoin as its public distributed ledger that is usually managed by a peer-to-peer network. In the distributed ledger, transactions are organized into blocks that are linked together into a chain. In a blockchain, transactions are validated and recorded by distributed consensus in the peer-to-peer network, eliminating the need for a trusted central entity.

Since 2008 this technology developed rapidly and Buterin, (2013) suggests second-generation blockchain that allows users to write more sophisticated smart contracts, thus creating automated digital rules such as invoices that pay themselves when a shipment arrives. Once transactions are validated, they become irreversible, verifiable, permanent, and secure on the blockchain.

Swan (2016) supports this finding with further additions of these characteristics, blockchain for empowering financial transactions.

Furthermore, Tapscott (2016) and Vigna (2015) accentuate as blockchain technology advances, it becomes capable of tokenizing and decentralizing not only money but also other scarce assets, significantly expanding its disruptive potential. Blockchain get the ability to restructure rules of trust around which society manages the exchange of values.

Tapscott (2016) substantiates why new opportunities of blockchain interested companies from different sectors of the economy. This is a number of factors: potential of crypto-currency is particularly interesting and at the same time it is dangerous for banks, as their appearance radically changes the existing banking business model, costs can be reduced through cost-saving technology and blockchain can eliminate the intermediary functions currently performed by financial sector.

Therefore, trade finance is one of the most promising areas of adoption blockchain. Supply chain financing are complex and face multiple uncertainties (Manuj \& Mentzer, 2008). A major objective of supply chain management is also to reduce risks. Among the various risks that organizations face include relational risks such as a business partner's engagement in opportunistic behavior (e.g., cheating, distorting information) (Baird \& Thomas, 1991; Bettis \& Mahajan, 1985; Svensson, 2000).

\section{BACKGROUND INFORMATION ABOUT SOFTWARE PRODUCTS IN TRADE FINANCE}

Trade is risky, takes time and requires many accompanying documents. That's why most factoring organizations, medium and even large banks prefer cooperation with a provider of platforms, rather than developing their own solution.

The created platforms allow implementing information flows of events that initiate financing processes. They are often software products of startups. In another case, they are software products of companies that provide electronic trading platforms to support trade finance operations (for example, Propell, CRX markets, Kyriba, Prime revenue, Tower trade, Orbian, Tungsten, etc.). These companies offer platforms that connect all parties together to simplify the signing and approval of documents accompanying trade finance and facilitate reconciliation process, invoices, credit notes, deliveries, payments, etc. Integration of all related information between supply chains is carried out with help of platforms (Del Prete S., 2014.)

Such support of trade financing operations gives many advantages to its participants. But this implies the presence of an additional intermediary - a company that creates software solutions and maintains information and technical support for platforms. For all this, banks and factoring organizations incur fixed costs.

There is a need to create an ecosystem for the effective implementation of functions in trade finance (BIS, 2014). Such ecosystem should maintain data confidentiality and be accessible to small, mediumsized enterprises and intermediaries. The development of blockchain has given a new impetus to participants of trade finance process to introduce innovative solutions into their business processes.

At present, the following areas of application of blockchain technology in trade financing and monitoring of supply chain can be identified:

1. Development by banks of their own solutions for improving trade finance processes.

As blockchain technology has developed, banks have taken their own steps to introduce innovative solutions in trade finance. Standart Chartered Bank, DBS Bank, Infocomm Development of Singapore became the first participants of the ecosystem to 
conduct trade financing operations using the technology of decentralized registries based on the Ripple blockchain. This allowed the market participants to assess the advantages of closed blockage in the conduct of financial transactions while maintaining commercial confidentiality. After that, other banks predominantly from the Asia-Pacific region began to develop and use blockchain to upgrade the process of trade finance and other areas of its activities.

1. Banks such as Barclays Bank with the help of the Wave start-up, Societe Generale and ING Bank (Easy Trade Connect platform on Ethereum blockchain), Sberbank (Masterchain platform) have created their own platforms for simple, fast and safe trade financing. (Groenfeldt, T.0; 2017 Walport, M.)

2. IBM and maersk apply blockchain to container shipping. Forbes. Retrieved from https://www. forbes.com/sites/tomgroenfeldt/2017/03/05/ibmandmaersk-apply-blockchain-to-containershipping/.

2. Association of banks in the blockchain consortiums.

Banks perform the role of financial guarantor and payment operator in the field of trade finance, so their goal is not to create and maintain their own technological solutions. So they began to join already created blockchain -platforms, possessing the properties of trust, transparency and impersonality of decisions. Among the largest consortiums R3 and Hyperledger, which have already developed several software solutions for banks and businesses, including the Corda and Digital Trade Chain blockchain platforms, to support trade finance processes(Walport, M., 2015)

Increasing the number of banks increases the security of the blockchain -platforms. The security of the blockchain network allows for achievement of consensus among its participants and should be provided primarily through economic means: an attack on the network must be too expensive and its protection more profitable.

3. Creation and development of new projects to optimize the processes of trade financing.

At the moment, companies already exist (for example, ModulTrade, Eximchain, Handelion and others) working on the blockchain-platforms that provide documentary support for trade finance and assume transactions through the tokens issued by these companies within the platforms.

In addition, many platforms (Waves, Universa, Rootstock, Codius, Agrello, Symbiont, BitShares, Eximchain, Imandra Contracts, AntShares, etc.) allow you to create smart contracts without special technical skills and store data in a decentralized repository.

\section{AREAS AND WAYS OF BLOCKCHAIN APPLICATION IN TRADE FINANCE}

The approach of the study is aimed at improving the existing model of trade finance based on document transactions in blockchain. Having compiled models of interaction of participants in trade finance with blockchain, we define ways of improvement modern financial instruments of trade finance without limitations of previous models. With this aim, we chose two the most common trade finance instruments: factoring and letter of credit (LC).

\subsection{Area 1. Factoring}

Depending on the trade finance instrument used with the use of blockchain, the interaction of participants may be different. The interaction in factoring between participants with limited capital: the buyer, the supplier and the factoring organization (Factor, Figure 1), is the exchange of documents in the order established by smart contracts.

Smart contracts downloaded to the network use accounting documents, invoices, etc. at the entrance with an agreed format. For each delivery of goods based on key fields, a hash is generated using the algorithm. The smart contract records the hash of the delivery, all amounts in the document's currency, posting dates that correspond to amounts. If the hashes match, then this is a confirmation of successful delivery of the goods. After that, the factor pays the supplier the necessary amount specified in the documents.

To become a new member of the block, it is necessary to create a node and connect it to the company's own information system for data exchange with other network members. In addition, all participants have a duty to maintain the system, so the mining is carried out by the parties to the trade finance transactions themselves. 


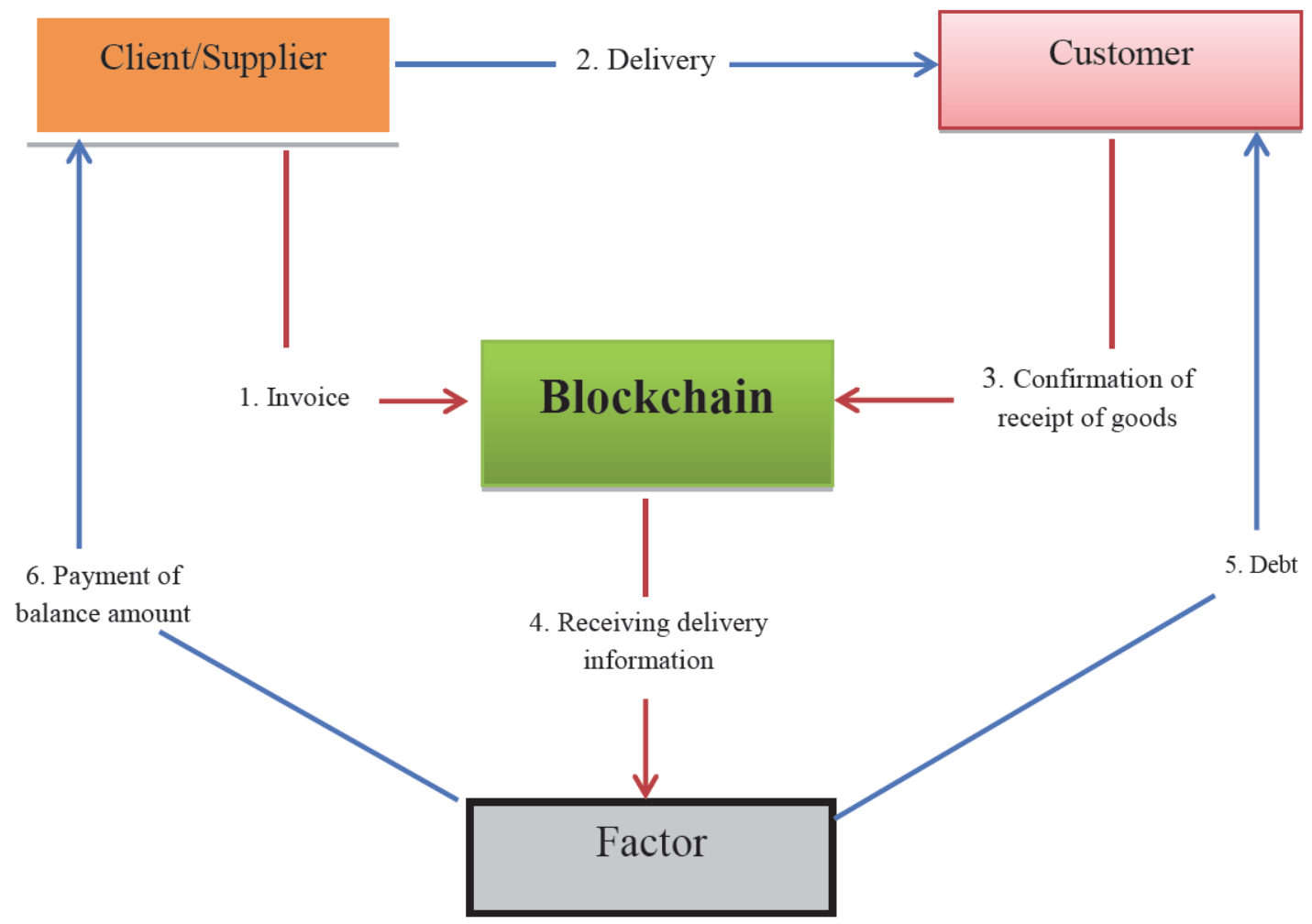

Figure 1: The interaction of participants in factoring with blockchain.

\subsection{Area 2. Digital Letter of Credit}

LCs are the most common trade finance product provided by banks. The importer initiates the LC transaction (Figure 2) by having its bank issue the instrument to the exporter (Gregg B., 2015.). The LC guarantees that the issuing bank will pay the agreed contract amount when the exporter proves that it delivered the goods, for example, by providing shipping documents confirming the arrival of the goods in the destination country. To cover the risk that the issuing bank will not pay, an exporter may have a bank in its own country confirm the LC, in which case the confirming bank agrees to pay the exporter if the issuing bank defaults. The cooperation model is coming more cumbersome, and therefore blockchain application is even more important for effectiveness of trade finance processes.

The process of executing a smart contract in this example is as follows:

1. The buyer-importer of services fills out application for opening of a digital LC, which specifies the details of the seller-exporter, terms of the contract: period, amount, and other required characteristics. Then the issuing bank considers the application and, if the decision is positive, confirms the application and opens a digital letter of credit (item 3 - Figure 2)

2. The information is added to the block and is visible to the participants, including the negotiating bank. After seller-exporter sends documents to the bank about shipment of the goods (for example, an invoice), the bank transfers the corresponding amount to its client and executes a digital LC (item 6 - Figure 2).

The process of interaction of participants may differ depending on the connection to the network of the seller or buyer and the trade finance instrument used. The blockchain modernizes the process of trade finance. Each of these areas of blockchain application solves the problems in different ways, but the goal for all is the same - optimization of the processes associated with supporting supply chain financing.

\section{IMPROVING BLOCKCHAIN TRANSACTIONS IN TRADE FINANCE}

The adoption blockchain into various instruments of trade financing gives a competitive advantage to banks and their customers. And at the same time, we can identify some defects of algorithm of interaction trade finance participants based only on document transactions. We formed proposals concerning the 


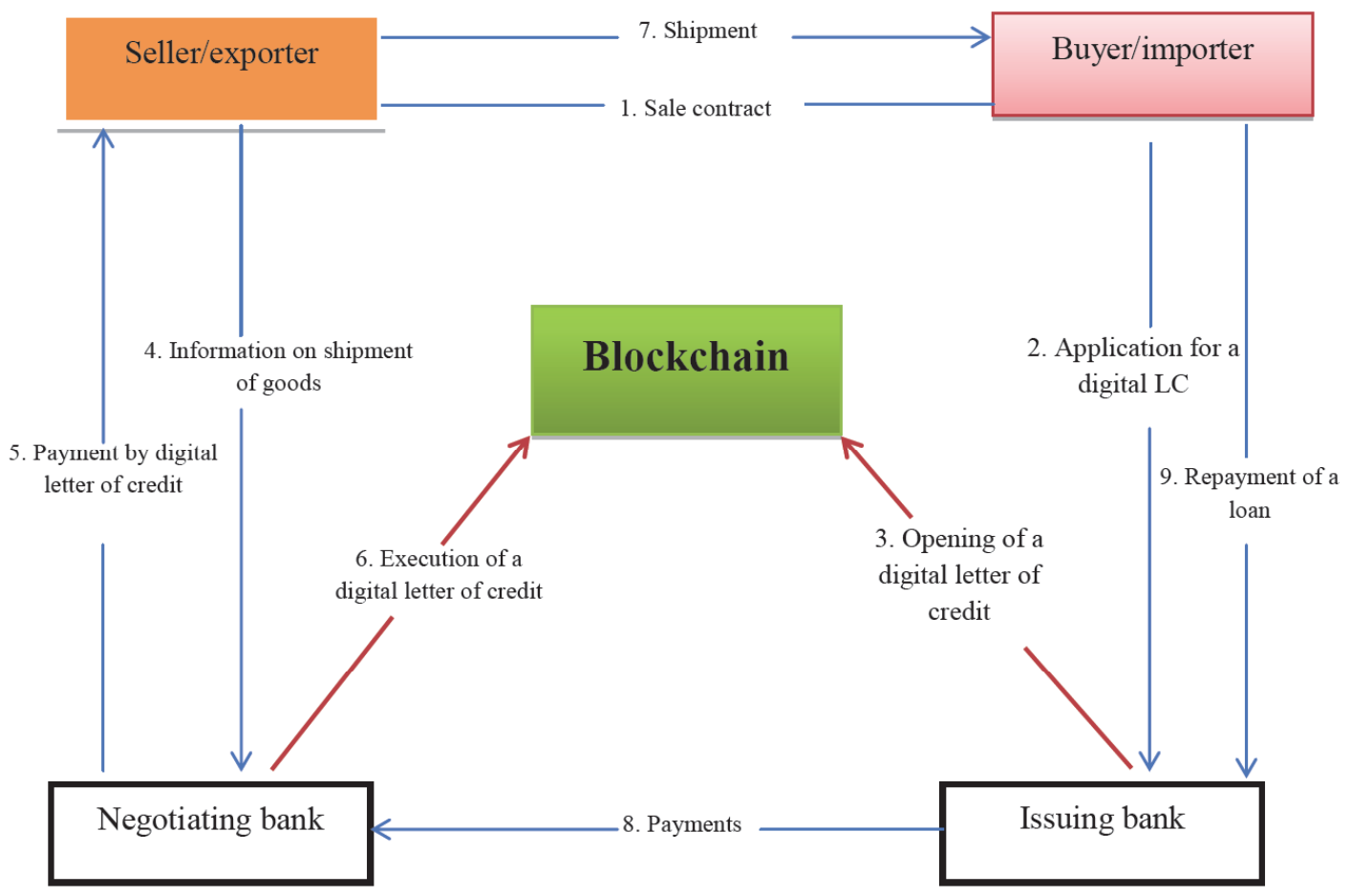

Figure 2: Interaction of participants of trade finance with a LC with blockchain application.

further more effective application of technology in financing of the supply chain.

\section{Increase number of participants.}

Increasing number of participants raises the level of network trust with an increase cybersecurity of blockchain. Thus, the probability of an attack of $51 \%$ (the generation of blocks by a miner who owns more than $50 \%$ of computing power, without confirmation by participants of blockchain) due to collusion between participants becomes zero. Therefore, the main defense is to involve as many independent participants in the system as possible as they have neither the opportunity nor the occasion to come to an agreement.

2. Add blockchain the ability to conduct transactions in electronic fiat money or in a digital currency, which is pegged to fiat money.

Increasing cybersecurity and expanding number of participants in a decentralized network allows the introduction of a payment system. Payments for trade financing transactions should be coded in smart contracts (Möser M., 2014). The ability to conduct transactions on the platform will further accelerate and simplify the process of trade finance.

3. Establishment of arbitration on platform itself, which allows resolving main conflict situations without court involvement.
Although smart contracts are performed in a decentralized environment, eliminating the human factor, it is important to understand that there are many cases that may require intervention from outside network. Trade finance in blockchain is needed for a decentralized system of arbitration, which allows the most reasonable and impartial settlement of disputes that often arise in the financing of supplies.

If logic of the execution of smart contract is not clearly defined, parties to the agreement may be involved in conflict situation, which is common in processes associated with transfers of things that have value. In arbitration practice, there are clear regulatory mechanisms for such issues. Parties with disagreements can resolve them through an arbitration court. Similar templates should also be implemented in the digital environment. The system of arbitration in a developed ecosystem should allow its participants to resolve arising disputes directly on the platform. This requires an arbitration system consisting of several levels. Its structure can be approximately the following: the first requires the participation of three to five arbitrators (organizations that make the final decision), the second - a wider range of entrusted participants in an odd number, except the challenging parties.

In accordance with the basics of digital economy, arbitrators should be selected using mathematical algorithms that analyze their reputation, area of competence and practical experience in this jurisdiction 
and sector of economy. To exclude a corrupt component, the digital arbitration system should hide the legal persons in case, for the purpose of an unbiased investigation of the facts in the case. In order to encourage organizations and experts to participate in digital arbitration, the parties to dispute are obliged to remunerate arbitrators at the end of process. If refusal to accept digital arbitration, parties should resort to existing traditional conflict resolution mechanisms. Thus, the spoiled reputation of the company, which went beyond blockchain platform and lost dispute, will affect company's business reputation and, possibly, rates of trade finance and further development of business.

\section{CONCLUSIONS}

This study explores the multiple the advantages and areas of blockchain application in trade finance, as well as further prospects for using technology in this area: increasing cybersecurity, performing transactions in blockchain, and introducing an arbitration dispute resolution mechanism within blockchain platform.

Blockchain with a high level of functionality in trade finance processes reduces processing time for documents, transaction costs and increases level of transparency. There remains the question of further implementation of the prospects for using technology. The implementation of blockchain into the financial sphere is not easy. And the first limitation is not a technical problems. Blockchain implies transparency of all financial transactions. And to work, in which the actions of all participants are recorded reliably, not all are ready.

\section{REFERENCES}

Baird, I. S., \& Thomas, H. 1991. What is risk anyway? Using and measuring risk in strategic management. In R. A. Bettis, \& $\mathrm{H}$. Thomas (vol. Eds.), Risk, strategy and management: 24. Connecticut: Jai Press Inc.

Bettis, R. A., \& Mahajan, V. 1985. "Risk/return performance of diversified firms. Management Science" 31(7): 785-799. https://doi.org/10.1287/mnsc.31.7.785

Trade Finance: Developments and Issues. BIS. 2014. Technical Report, Bank for International Settlements. URL: https://www.bis.org/publ/cgfs50.htm (date of access 17.05.2018)
Buterin. 2013. Mastercoin: A Second-Generation Protocol on the Bitcoin Blockchain. URL: https://bitcoinmagazine.com/ articles/mastercoin-a-second-generation-protocol-on-thebitcoin-blockchain-1383603310/. (date of access 18.05.2018)

Del Prete S., Federico, S. 2014. Trade and Finance: Is There More than Just Trade Finance? Evidence from Matched Bank-firm Data. Banca d'Italia, mimeo.

Easy Trading Connect on the verge of digitalising an age-old sector. URL: https://www.ing.com/Newsroom/All-news/Easy-TradingConnect-on-the-verge-of-digitalising an-age-old-sector.htm date of access 18.05.2018)

Gregg B., Hou G., Lalji Z., Xiulin S. 2015 "Supply chain financeemergence of a new competitive landscape". McKinsey \& Co. 8 (22): p. 32-38.

Groenfeldt, T. 2017. IBM and maersk apply blockchain to container shipping. Forbes. URL: https://www.forbes.com/sites/ tomgroenfeldt/2017/03/05/ibm-and-maersk-apply-blockchainto-container-shipping/\#432771513f05. URL and (date of access 01.05.2018)

Koetsier, J. 2017. Blockchain Beyond Bitcoin: How Blockchain Will Transform Business in 3-5 Years. June 14 https://www.inc.com/john-koetsier/how-blockchainwilltransform-business-in-3-to-5-years.html

Lee, David K. C. 2015. Bitcoin, Innovation, Financial Instruments, and Big Data / Handbook of Digital Currency 1st Edition. Academic Press.

Lee. L. 2016. Market New Kids on the Blockchain: How Bitcoin's Technology Could Reinvent the Stock Market. Hastings Business Law Journal, 12 (2).

Manuj, I., \& Mentzer, J. T. 2008. "Global supply chain risk management. Journal of Business Logistics". 29(1):133-155. https://doi.org/10.1002/j.2158-1592.2008.tb00072.x

Möser M. Möser M, Böhme R., Breuker D. 2014. Towards risk scoring of bitcoin transactions.International Conference on Financial Cryptography and Data Security. https://doi.org/10.1007/978-3-662-44774-1_2

Nakamoto, S. 2008 Bitcoin: A Peer-to-Peer Electronic Cash System. / URL: https://bitcoin.org/bitcoin.pdf (date of access 18.05.2018)

Swan,M. 2016. Blockchain Blueprint for a New Economy. O'Reilly Media, Inc.

Svensson, G. 2000. :A conceptual framework for the analysis of vulnerability in supply chains". International Journal of Physical Distribution and Logistics Management, 30(9), 731749.

https://doi.org/10.1108/09600030010351444

Tapscott, D. 2016. How will blockchain change banking? How won't it? https://www.huffingtonpost.com/don-tapscott/how-willblockchain-chang_b_9998348.html (date of access 18.05.2018)

The blockchain revolution in trade finance. URL: https://www.barclayscorporate.com/insight-andresearch/trading-and-exporting/blockchain-revolution-intrade-finance.html (date of access 18.05.2018)

Vigna P, Casey M. 2015. The Age of Cryptocurrency: How Bitcoin and Digital Money Are Challenging the Global Economic Order St. Martin's Press.

Walport, M. 2015. Distributed ledger technology: Beyond block chain // Government Office for Science.

\section{DOI: https://doi.org/10.6000/1929-7092.2018.07.47}

(c) 2018 Bogucharskov et al.; Licensee Lifescience Global.

This is an open access article licensed under the terms of the Creative Commons Attribution Non-Commercial License (http://creativecommons.org/licenses/by-nc/3.0/) which permits unrestricted, non-commercial use, distribution and reproduction in any medium, provided the work is properly cited. 